\title{
Analysis of the Degree of Integration of Multicultural Education Contents into Ethiopian Primary Teacher Education Curricula
}

\author{
Robsan M. Egne (PhD) \\ Department of Curriculum Studies and Teachers' Professional Development, College of Education and \\ Behavioral Sciences, Arsi University, Ethiopia
}

\begin{abstract}
Addressing issues of diversity in the teacher education system of multicultural countries is high on the agenda worldwide because of the growing connectedness due to globalization. This suggests the importance of integrating issues of diversity in the teacher preparation programs of particularly multicultural states. It is in light of the above notion that this study investigates the extent to which issues of multicultural education are effectively incorporated into the primary teacher education curricula of Ethiopia in order to enhance the learning outcomes of students through addressing their cultures. The contents of five sample primary teacher education curricula were analyzed based on Banks' $(2001,2010,2014)$ four approaches to the integration of issues of multicultural education into teacher education curricula. To that end, in order to conduct the content analysis, a clear and valid coding sheet was prepared. Ten coders were selected and adequate trainings were given to them in order to help them effectively code the sample teacher education curricula. As such, the sample teacher education curricula were critically analyzed by two anonymous coders separately and then inter-rater reliability was calculated based on Sarantakos' (2005) $80 \%$ standard. Results of the study revealed that basic elements of multicultural education are mostly missing in the current Ethiopian primary teacher education curricula. Conclusions and implications were drawn based on the findings of the study.
\end{abstract}

Keywords: analysis, curriculum, multicultural education, primary teacher education, learning outcomes

DOI: $10.7176 / \mathrm{JPCR} / 50-03$

Publication date:August $31^{\text {st }} 2020$

\section{Introduction}

\subsection{Background and Rationale of the Study}

Addressing diversity in the teacher education system of countries is high on the agenda worldwide because of the growing connectedness due to globalization. This suggests the importance of utilizing issues of diversity as resources in the teacher preparation programs of particularly multicultural states (Gay, 2013; Vavrus, 2002; Zeichner et al., 1998). Of course, using diversity as a resource in a teacher education program is a debatable matter. This is because there are scholars who support it (Egne, 2015; Gay, 2013; Mergo, 2008; Rosaen, 2003) and at the same time there are people who consider it as a threat to the national unity of the country under consideration (Chavez, 1998; Schlesinger, 1992; Sowell, 1993). This article takes the first position as a starting point.

While addressing issues of diversity in a teacher preparation program have received much attention in the high-income countries (Rosaen, 2003; Zeichner et al., 1998), relatively little is known about the utilization of diversity as a resource in the teacher education system of low-income countries. Hence, through this article, I want to contribute to a better understanding of teacher education system in low-income countries by presenting the results of a study on primary teacher education in Africa by taking Ethiopia as a case.

Ethiopia is located in the horn of Africa and shares boundaries with Djibouti, Eritrea, Kenya, Somalia, Sudan, and South Sudan. According to the most recent, 2007, Population and Housing Census, Ethiopia has a total population of 73,918,505. Ethiopia is the second most populous nation in Africa, only preceded by Nigeria, and has more than 80 ethnic groups living together. The major ethnic groups are: Oromo (34.5\%), Amhara (26.9\%), Somali (6.2\%), Tigre (6.1\%), Sidama (4\%), Guragie (2.5\%), Wolaita (2.3\%), Hadiya (1.7\%), Afar (1.7\%), and Gamo (1.5\%) (Federal Democratic Republic of Ethiopia Population Census Commission, 2008, p. 16). It can be characterized as a mosaic of nations, nationalities and peoples, as well as linguistic groups (Egne, 2015). Well over 80 different languages are spoken in the country constituting 22 Cushitic, 18 Omotic, 18 Nilo-Saharan, and 12 Semitic languages (Ethiopian Ministry of Information, 2004). With regard to major religious affiliations, $43.5 \%$ of the total population is Orthodox Christian and 33.9\% is Muslim. Protestant and traditional religion followers account for $18.6 \%$ and $2.6 \%$, respectively (Federal Democratic Republic of Ethiopia Population Census Commission, 2008, p. 17).

However, due to the historical landscape of the country, this diversity had not been addressed in the education system of the country (Egne, 2014a; Kibret, 2019). In connection to the coming to power of the Ethiopian People's Revolutionary Democratic Front in 1991 with the notion of ethnic-federalism, a new constitution, education and training policy, and cultural policy have been formulated. These government policies have emphasized issues of diversity more than ever (Egne, 2010). For instance, with regard to the importance of addressing issues of diversity, the current Ethiopian constitution states that "the government shall have the duty to support, on the basis of equality, 
the growth and enrichment of cultures and traditions that are compatible with fundamental rights, human dignity, democratic norms and ideals, and the provisions of the constitution" (Federal Democratic Republic of Ethiopia, 1995, Article 91, p. 133). Besides, the constitution asserts that "education shall be provided in a manner that is free from any religious influence, political partisanship or cultural prejudices" (Federal Democratic Republic of Ethiopia, 1995, Article 90).

Similarly, the education and training policy of Ethiopia states "to provide education that promotes democratic culture, tolerance and peaceful resolutions of differences that raises the sense of discharging societal responsibility" (Federal Democratic Republic Government of Ethiopia, 1994, Article 2.2.9, p. 10). In addition, the same education and training policy illustrates "to provide education that can produce citizens who stand for democratic unity, liberty, equality, dignity and justice, and who are endowed with moral values" (Federal Democratic Republic Government of Ethiopia, 1994, Article 2.2.10, p. 10). Furthermore, the 1997 cultural policy of Ethiopia proposes strategies, such as inclusion of cultural themes into the school curricula with the intention of integrating culture with education and thereby shape the youth with a sense of cultural identity as well as the transmission of educational programs that reflect the various cultures of the country through mass media (Federal Democratic Republic of Ethiopia, 1997, p. 8).

According to Pankajam (2005), children learn more effectively in a stimulating and in an enriched environment. This implies the need for addressing the learning styles of students from diverse backgrounds (Banks, 2006; Zirkel, 2008) in order to enhance their level of socialisation as well as their learning outcomes. This, in turn, suggests the importance of improving the teaching competences of primary school teachers through addressing important teaching skills such as cooperative learning, learning communities, and service learning (Zirkel, 2008) in the teacher preparation programs. This is guided by the notion that teacher education has a multiplier effect and for the necessary multiplication to take place (Egne, 2014a), it's important to educate prospective teachers in a way in which they get an in-depth understanding about how to entertain the needs and the interests of students with diverse backgrounds.

It can be argued that teachers have professional and moral obligations to treat all students in a fair way irrespective of their circumstances (Egne, 2015). Moreover, teachers are the lifeblood in the efforts made to ensure the quality of education. Besides, teachers are supposed to facilitate the cognitive, physical and moral development of all students in order to enhance their learning outcomes particularly in the lower grades. Furthermore, teachers are assumed to be guardians as well as transmitters of cultural heritage in a fair way in order to ensure its sustainability. In support of this notion, Avalos (2000) asserts that teachers are assumed to be inter-cultural communicators and mediators with respect to cultural differences in the classrooms and beyond. What is more? Teachers can make or break a nation depending on the kind of citizens they produce.

While primary education is assumed to be the foundation for the well-rounded development of the child, to the best of my knowledge, there is no study that critically examined the degree to which issues of multicultural education are effectively integrated into the teacher education programs of Ethiopia as a means to foster the learning outcomes of children from diverse backgrounds. This makes analyzing the extent to which issues of diversity are integrated in the primary teacher education systems of the country quite interesting and timely. To this end, I used multicultural education as a guiding concept as it relates to the basic values and principles incorporated into the Ethiopian government's diversity-driven policies. In addition, multicultural education is used as an analytical tool as it is assumed to help get a better understanding about the degree to which the diverse nature of the country is effectively entertained in the primary teacher education system.

Furthermore, although issues of multicultural education can encompass culture, ethnicity, language, gender, disability, race, religion, sexual orientation, and other forms of diversity (Banks, 2010; Egne, 2014b, 2015), attention in this study is specifically given to issues related to ethnicity, culture, and language. This is because in Ethiopia, these three concepts play pivotal roles in determining relationships among the various ethno-cultural groups of the country (Egne, 2017). Moreover, the current Ethiopian government policies emphasize ethnicity, language, and culture more than the other elements of diversity as they have been used as the core criteria for determining local and regional boundaries.

\subsection{Research Problem and Research Questions}

The core intention of this research was to examine the extent to which multicultural education contents are incorporated into primary teacher preparation programs of Ethiopia in order to effectively prepare prospective teachers for teaching in a multicultural setting. Teacher education is assumed to play a key role in building a country through preparing and supplying teachers who, in turn, contribute to the production of informed and ethical citizens. As suggested by Zeichner et al. (1998, p. 164), "a commitment to multicultural education without a solid commitment to the activity of teacher education is not sufficient".

Producing competent teachers has become a global concern since all countries tend to use education as a tool to alleviate their problems and thereby foster the building of effective political and socio-economic institutions (Vavrus, 2002). According to Banks (2006), one of the major problems facing nations throughout the world is how 
to recognize and legitimize ethnic and cultural differences and yet construct an overarching national identity that incorporates the perspectives of the diverse groups that compose the country. This suggests the importance of balancing unity and diversity particularly in nations characterized by diversity (Banks, 2001, Egne, 2014b, 2015). This could be realised, amongst other things, through effectively integrating issues of diversity into teacher education programs at all levels (Zeichner et al., 1998) to produce citizens who have intercultural competencies (Bennett, 2011), as well as show dedication to their own cultural identities and to national unity (Banks, 2006).

This being the case, whether there exists a gap in the Ethiopian primary teacher education curricula with respect to maintaining the right balance between cultural identities and national unity is not yet well studied. Moreover, whether or not the primary teacher education curricula effectively address cross-cultural education in order to teach Ethiopian children about mutual understanding and tolerance is not researched. In light of the above arguments, this research paper intends to answer the following research questions.

- To what extent are issues of multicultural education integrated to the current Ethiopian primary teacher education curricula?

- Is there any significant difference among the Ethiopian primary teacher education curricula in terms of addressing issues of multicultural education?

\section{Review of Related Literature}

\subsection{The Concept of Multicultural Education}

The concept multicultural education has been defined differently by different scholars at different times (Banks, 2014; Parekh, 2006; Torres, 1998) due to the complexity and richness of the field. As a field of study, multicultural education embraces a multitude of themes (Egne, 2015) which makes it difficult to group the various definitions of the concept into distinct categories. According to Banks (2010), multicultural education is an idea, an educational reform movement, and a process whose major goal is to change the structure of educational institutions in order to provide an equal chance for all students with diverse backgrounds and interests to achieve academically in school. In this study, the three perspectives proposed by Banks (2010) to conceptualise multicultural education are used as a basis to discuss definitions of multicultural education. As asserted by Banks (2008), the heart of a field of study is its key concepts, generalisations, and principles. Hence, culture is a basic concept of multicultural education. Besides, as stated by Parekh (2006), multiculturalism is not about difference and identity per se but about those that are embedded in and sustained by culture; that is, a body of beliefs and practices in terms of which groups of people understand themselves and the world and organize their individual and collective lives.

As an idea, a concept, or a philosophical outlook, multicultural education refers to a set of beliefs and ways of thinking that recognize as well as value the relevance of cultural diversity in shaping the lifestyles, social experiences, individual and collective identities, and the provision of educational opportunities for individuals and groups alike (Egne, 2015). According to Bennett (2011, p. 10), "multicultural education has ideological overtones based on democratic ideals that are lacking in less controversial content areas of the curriculum, such as mathematics, reading, or spelling". The four core values which provide a philosophical framework for multicultural education are: acceptance and appreciation of cultural diversity; respect for human dignity and universal human rights; responsibility to the world community; and respect for the earth (Bennett, 2011).

The conceptualisation of multicultural education as an educational reform movement (Banks, 2010; Terefe, 2016) entails analysing and restructuring the existing education system in order to make it reflective of the social, cultural, ethnic, linguistic and other characteristics of the students that attend it. Nieto and Bode (2010) define multicultural education as a process of comprehensive school reform and basic education for all students. It challenges and rejects racism and other forms of discrimination in school and society and accepts and affirms the pluralism that students, their communities, and teachers reflect. Multicultural education permeates school curricula and instructional techniques as well as the interactions among teachers, students, and families and the very way that schools conceptualize the nature of the teaching and learning process. Because it uses critical pedagogy as its underlying philosophy and focuses on knowledge, reflection, and action as the basis for social change, multicultural education promotes democratic principles of social justice. Nieto and Bode's (2010) definition highlights seven core characteristics of multicultural education: antiracist education; basic education; inclusive education; education which has a pervasive scope; education for social justice; education which ensures continuity; and education which applies critical pedagogy.

Grant and Sleeter (2010) argue that multicultural social justice education deals with oppression and social structural inequality which is based on social and other markers. It aims at preparing future generations to take informed actions to enable the society to serve the interests of all groups of people, particularly those who are underserved. Multicultural education can also be discussed by considering it as a process rather than a product. This means that its core goals, i.e. provision of educational equity and social justice, cannot be fully realized. Banks (2010) asserts that educational equality, like liberty and justice, are ideals toward which human beings work but never fully attain. In other words, since the goals of multicultural education can never be fully attained, it is important to work continually to increase educational equality and access for all students. 
From the personal development perspective, Reysen and Katzarska-Miller (2013, p. 858) argue that "as the world becomes increasingly interconnected, exposure to global cultures affords individuals opportunities to develop global identities". Hence, conceptualising multicultural education as global education may be seen from the perspective of students' development of inter-cultural competence as a consequence of cross-cultural education. In other words, the experiences that students get from different perspectives while pursuing intercultural education may help them develop transnational competence. Such competence becomes more important in this globalized world in terms of helping learners think beyond their specific cultural boundaries. This means that the learners develop flexible and multiple identities or cosmopolitan identities, which are the characteristic of global citizenship.

\subsection{Multicultural Teacher Education}

Teacher education institutions around the world particularly those which are situated in multicultural states are expected to provide multicultural teacher education to entertain the needs of marginalized groups (Egne, 2014a; Vavrus, 2002). To this end, it is important that teacher education institutions reform their policies, curricula, teaching approaches as well as assessment techniques. Sobel et al. $(2011$, p. 435) are of the opinion that "while effective teachers are the key to meeting the needs of diverse learners and critical in preparing these learners for the twenty-first century, teacher preparation programs must examine how equipped they are in modeling and teaching in culturally responsive practices". Of course, learning to become an effective teacher is a long and complex process.

Research works (Egne, 2017) focusing on the impacts of multicultural education on prospective teachers' attitudes and knowledge on issues of diversity are growing. However, most of the outcomes of these studies imply that the effects are often not positive and clear. Multicultural teacher education programs are often developed for students with diverse backgrounds in a fragmentary manner (Egne, 2014a; Gay, 2013). This may suggest the importance of reviewing previous studies on multicultural teacher education to have a better understanding of whether multicultural teacher education courses and programs have significant effects on prospective teachers' knowledge, attitudes, skills, and perceptions with respect to issues of diversity. Such a review is also important to identify the knowledge gap in multicultural teacher education systems thereby find means through which the gaps could be effectively bridged.

As suggested by Yang and Montgomery (2013), since attitudes are central to multicultural education, it is important to emphasize those attributes in multicultural teacher education. Besides, a study conducted by Elmeroth in Sweden (2009, p. 333) revealed that "students with a negative or mono-cultural attitude need teachers who can act as active role models in creating a multicultural attitude". But the problem is deciding how many multicultural courses will enable prospective teachers to bring the desired attitudinal changes towards diversity as well as how to measure changes in attitudes. As illustrated by Yang and Montgomery (2013), a survey study conducted on the education system of Spain indicated that taking a single course on multicultural issues cannot prepare teachers for cultural diversity. Similarly, Reed (1993) conducted a study on the extent to which pre-service teachers have changes in attitudes and perceptions following a multicultural course. To this end, she administered pre and post surveys on pre-service teachers taking the course which showed that a single course in multicultural education does not change deep-seated personal feelings about disadvantaged students.

On the contrary, according to Garmon (2005), no matter how keen we are in designing and presenting multicultural teacher curricula in a well-organized manner, there is no assurance that the trainees' learning outcomes will be successful in terms of preparing them to effectively teach in a multicultural setting. This is because individual prospective teachers respond to diversity courses or experiences depending on a number of personal attributes. This means that each teacher candidate brings his/her own preconceived attitudes, beliefs, values, experiences, and dispositions, and he/she interprets the lessons through these filters (Garmon, 2005; Rosaen, 2003). Therefore, if we want to bring real and lasting attitudinal changes in the prospective teachers towards diversity, the lessons we present to them must challenge those deep-seated preconceived attitudes which the candidates bring to the classroom situations.

\subsection{Strategies to Incorporate Multicultural Education Contents into Teacher Education Curricula}

As it is known, different writers (Cochran-Smith, 2003; Garmon, 2005; Zeichner et al., 1998) suggest various strategies to integrate issues of multicultural education into teacher education curricula. However, in this study, Banks' $(2001,2006,2014)$ four approaches to the integration of multicultural education issues into teacher education curricula were used as analytical tools. As such, in the following, I will try to present and discuss each of them briefly. According to Banks $(2001,2006,2014)$, there are four approaches to the integration of issues of diversity into teacher education curricula. As Bieger (1995) claims, Banks' four approaches are hierarchically arranged with respect to the extent to which issues of multicultural education are emphasized in a given curriculum. In the following, I briefly discuss each of the four approaches and highlight how they will be applied in this article.

The contributions approach signifies what minority groups in a given multicultural society could contribute to the dominant culture in order to get a sense of belonging (Jenks et al., 2001). This approach is mainly used when 
a teacher education institution attempts to integrate issues of multicultural education into the mainstream teacher education curricula for the first time (Banks, 2006). It involves the incorporation of various ethnic group cultures into the existing teacher education curricula as supplements in an attempt to help the prospective teachers get different perspectives. In this article, the core indicator that was used with regard to this approach is analyzing the degree to which the cultures of, at least, the major ethnic groups of Ethiopia are incorporated into at least some units of the current primary teacher education curricula.

The addition approach deals with the insertion of ethnic contents, concepts, themes, and perspectives (Banks, 2001, 2006) into the existing teacher education curriculum without changing its fundamental aims, contents, and structures. As asserted by Jenks et al. (2001), the addition approach emphasizes the adding on of multicultural elements into existing programs in order to address what has been ignored. Similarly, as explained by Banks (2006), this approach is often realized by the addition of a unit, or units to the existing teacher education curriculum without changing it significantly. The core indicator that was used in this research with respect to this approach is analysing the extent to which the diverse cultures of the Ethiopian society are incorporated into the existing primary teacher education curricula, at least, as an add-on.

The transformation approach is the level at which the structure of the curriculum will be significantly changed to enable students to view concepts from the perspective of various ethno-cultural groups (Bieger, 1995). According to Banks (2006), it is neither possible nor desirable to view each concept from the point of view of every ethnic group. Instead, the core objective is to enable prospective teachers to view issues of diversity from more than one perspective. The core indicator that was used in this research with regard to this approach is exploring the extent to which efforts are made to significantly change the basic components of the current Ethiopian primary teacher education curricula through integrating diversity-oriented contents and perspectives into them. The final approach is the social action approach and at this level students are expected to identify social problems and then make decisions and take action to solve them (Bieger, 1995). According to this approach, the main objective of the teaching and learning process is to empower students to analyze their social realities supported with appropriate decision-making skills (Banks, 2001). For this investigation, the indicator is analyzing whether components of the current Ethiopian primary teacher education curricula help the prospective teachers become critical thinkers who can effectively solve their societal problems.

To sum up, the four approaches were used as the core analytical tools to analyze the extent to which the multiplicities of the cultures of the Ethiopian society are represented in the primary teacher education curricula. Moreover, the four approaches were used to analyse whether multi-ethnic and multicultural contents are entertained in the Ethiopian primary teacher education curricular elements, such as objectives, contents, learning activities, instructional resources, and assessments in a harmonized manner.

\section{Methodology}

This research investigates the degree to which multicultural education components are incorporated into the current Ethiopian primary teacher education curricula. To that end, content analysis was used as a tool for data collection. This is because content analysis (Dejen, 2017; Egne, 2014a; Silverman, 2006) is an appropriate method of textual investigation. Thus, both the quantitative and the qualitative content analyses were employed to triangulate the results that are obtained through content analyses.

To this end, out of all the courses designed for the Ethiopian primary teacher education program or diploma in teaching (10+3 program), five courses, namely 'Action Research or Practical Research', 'Sociological Perspectives on Teaching and Learning', 'General Methods of Teaching', 'Special Needs Education', and 'Civic and Ethical Education' were taken as samples using a purposive sampling technique. The five courses were intentionally selected as samples due to the fact that they are more related to issues of multicultural education than the other courses designed for the diploma in teaching (10+3 program). In addition, all of the five courses were found to be more suitable for conducting the content analysis process as they are developed in modular form that give room for in-depth analyses. Furthermore, taking into consideration the dynamic nature of curricula, the entire contents of the sample texts were critically analysed. As a research method, content analysis is used differently by different scholars (Egne, 2014a). However, in this research, regarding the quantitative content analysis, Sarantakos' (2005) model that explains content analysis as a systematic, objective and quantitative method was used. Systematic refers to categorising and applying a set of procedures to all the contents to be analyzed; objective means that it is free from personal views; and quantitative means that it is counted in terms of numbers.

In order to puddle the results for the quantitative content analysis, a coding sheet, which consists of 12 items, was prepared in the form of a Likert-scale with five options (strongly agree, agree, undecided, disagree, and strongly disagree). The five alternatives were used to ensure relatively better flexibility in the coding of the sample texts. The coding sheet was prepared based on Banks' $(2001,2006,2014)$ four approaches to the integration of multicultural education contents into teacher education curricula. Each of the four core indicators were systematically repeated three times to check the consistency of the coders' responses. Accordingly, the first three indicators were framed based on the contributions approach whereas indicators number four, five and six were 
prepared in line with the addition approach. Indicators number seven, eight, and nine were designed based on the transformation approach whereas the last three indicators were set to address the social action approach (see Table 1 below). Each item in the coding sheet was judged for its validity, whether each of the items was developed based on the respective Banks' four approaches as well as the lucidity of the wording, by two senior colleagues in the areas of curriculum studies. The five modules were coded based on the indicators presented in Table 1 below.

Table 1: Indicators for the analysis of multicultural education contents in Ethiopian primary teacher education curricula

\begin{tabular}{|c|c|c|c|c|c|c|}
\hline \multirow[t]{2}{*}{ No } & \multirow[t]{2}{*}{ Indicators } & \multicolumn{5}{|c|}{ Options } \\
\hline & & $\begin{array}{l}\text { Strongly } \\
\text { agree }\end{array}$ & Agree & Undecided & Disagree & $\begin{array}{l}\text { Strongly } \\
\text { disagree }\end{array}$ \\
\hline 1 & $\begin{array}{l}\text { The cultures of the majority of Ethiopian ethnic } \\
\text { groups are incorporated into the objectives, } \\
\text { contents, learning activities, and assessments } \\
\text { of the primary teacher education curricula to } \\
\text { supplement the core themes of the mainstream } \\
\text { curricula. }\end{array}$ & & & & & \\
\hline 2 & $\begin{array}{l}\text { Multicultural-oriented concepts are entertained } \\
\text { in the current primary teacher education } \\
\text { curricula without giving much attention to their } \\
\text { deeper meanings. }\end{array}$ & & & & & \\
\hline 3 & $\begin{array}{l}\text { Discrete cultural artifacts such as the foods, } \\
\text { histories, dances, music, etc. of ethnic groups } \\
\text { (Oromo, Amhara, Tigre, Somali, Sidama, and } \\
\text { others) are incorporated into the primary } \\
\text { teacher education curricula to at least to make } \\
\text { the prospective teachers aware of them. }\end{array}$ & & & & & \\
\hline 4 & $\begin{array}{l}\text { Concepts that reflect the multi-ethnic and } \\
\text { multicultural nature of the Ethiopian society } \\
\text { are infused into the primary teacher education } \\
\text { curricula without changing their fundamental } \\
\text { frameworks. }\end{array}$ & & & & & \\
\hline 5 & $\begin{array}{l}\text { Words, phrases, and/or statements that address } \\
\text { the diverse cultures of Ethiopian people are } \\
\text { incorporated into the objectives, contents, } \\
\text { learning activities, and evaluations of the } \\
\text { current primary teacher education curricula to } \\
\text { help prospective teachers to see things from } \\
\text { different perspectives. }\end{array}$ & & & & & \\
\hline 6 & $\begin{array}{l}\text { Concepts that reflect the Ethiopian ethnic } \\
\text { groups' cultures are added to the primary } \\
\text { teacher education curricula in the form of } \\
\text { topics and/or units without changing them } \\
\text { substantially. }\end{array}$ & & & & & \\
\hline 7 & $\begin{array}{l}\text { The purposes, contents, learning activities and } \\
\text { assessment methods of the current primary } \\
\text { teacher education curricula are changed } \\
\text { fundamentally so as to enable prospective } \\
\text { teachers to view concepts, issues, and themes } \\
\text { from many ethnic groups' perspectives. }\end{array}$ & & & & & \\
\hline 8 & $\begin{array}{l}\text { The overall features (purposes, contents, } \\
\text { sequences, learning activities, instructional } \\
\text { resources, and evaluations) of the primary } \\
\text { teacher education curricula are completely } \\
\text { changed to make them responsive to the } \\
\text { cultures of the majority of Ethiopian peoples. }\end{array}$ & & & & & \\
\hline
\end{tabular}




\begin{tabular}{|c|c|c|c|c|c|c|}
\hline \multirow[t]{2}{*}{ No } & \multirow{2}{*}{ Indicators } & \multicolumn{5}{|c|}{ Options } \\
\hline & & $\begin{array}{l}\text { Strongly } \\
\text { agree }\end{array}$ & Agree & Undecided & Disagree & $\begin{array}{l}\text { Strongly } \\
\text { disagree }\end{array}$ \\
\hline 9 & $\begin{array}{l}\text { Contents that extend prospective teachers' } \\
\text { cognitions of the nature, development, and } \\
\text { complexity of the diverse Ethiopian society are } \\
\text { addressed in the primary teacher education } \\
\text { curricula. }\end{array}$ & & & & & \\
\hline 10 & $\begin{array}{l}\text { Contents and/or learning activities that help } \\
\text { prospective teachers to become active citizens } \\
\text { are addressed in the primary teacher education } \\
\text { curricula (change agent in striving to bring } \\
\text { equality, social justice, and democracy; respect } \\
\text { human rights; responsible in denouncing } \\
\text { stereotypes, ethnocentrism, unfairness, etc.; } \\
\text { competent in working effectively in a } \\
\text { multicultural setting). }\end{array}$ & & & & & \\
\hline 11 & $\begin{array}{l}\text { Contents which aimed at educating prospective } \\
\text { teachers to analyze about their social realities } \\
\text { thereby develop decision-making skills are } \\
\text { accommodated in the primary teacher } \\
\text { education curricula. }\end{array}$ & & & & & \\
\hline 12 & $\begin{array}{l}\text { Balance was maintained in borrowing core } \\
\text { elements of curriculum from international } \\
\text { perspectives and in incorporating Ethiopian } \\
\text { indigenous knowledge into the primary teacher } \\
\text { education curricula so as to produce } \\
\text { prospective teachers who have better } \\
\text { awareness thereby become forces of social } \\
\text { changes for the better. }\end{array}$ & & & & & \\
\hline
\end{tabular}

These twelve indicators were used to analyze the five sample texts

When it comes to selection of coders, ten with specialization in educational science were selected purposely due to the fact that all of them have adequate experience in teacher education and the relevance of their areas of specialization to the study under consideration. In addition, the coders were taken from two of the Ethiopian public universities: five from Arsi University and five from Adama Science and Technology University. They were given thorough training in how to code the sample texts. The training focused on establishing a common baseline through understanding how multicultural education is conceptualized in this study. In addition, the training emphasized understanding the essence of the coding sheet and how to use it in analysing the sample texts through checking off the five-point Likert scale. In order to ensure the validity of the coding process, each of the sample courses was coded by two coders separately. As part of the follow-up process of the coding procedure as well as for crosschecking purposes, I participated as a co-coder for each of the five texts.

The reliability of the coding process was checked using Sarantakos' $(2005$, p. 304$)$ standard, i.e. $80 \%$ as satisfactory. Thus, the two respective coders' level of agreement or the hit or miss between the coders in the respective courses was determined by comparing each of the percentage of concordance to $80 \%$. The assumption was that if the level of agreement between the two coders was less than $80 \%$, the coding process would be considered as unreliable. If the concordance between the two coders was equal or greater than $80 \%$, it was taken to be reliable. Based on the results, how multi-ethnic and multicultural contents are addressed in the current Ethiopian primary teacher education curricula is determined.

In addition, qualitative content analysis was employed to compare its results with the research findings obtained through the quantitative content analysis. The qualitative content analysis was made to analyze the degree to which issues of multiethnic and multicultural education are embedded in the latent contents of the sample texts. In other words, this part of the content analysis concentrated on the latent contents which are unobservable and that should be measured indirectly. Furthermore, unlike quantitative content analysis, qualitative content analysis gives the possibility to investigate words and images (Egne, 2014a). Qualitative content analysis may also help a researcher to explore the meaning and realities beyond the words and images. Hence, it was based on the above discussions that the qualitative content analysis was made in relation to Banks' four approaches to the integration of ethnic and multicultural contents into teacher education curricula.

In general, in this study, both qualitative and quantitative content analyses were made to get valid and reliable research results. This is guided by the notion that any researcher who engages in content analysis is expected to 
consider both the manifest and the latent contents of the document under consideration. This is also important to triangulate the results of the content analyses.

\section{Results and Discussions}

This section of the study deals with the findings of the study and the subsequent discussions and interpretations. To this end, results of the qualitative and the quantitative content analyses were presented, discussed, and interpreted. As such, in the case of the quantitative content analysis, since the final results of the coding process found to converge mainly to the option 'strongly disagree,' the five-point scale was reduced to a three-point scale to present the results in a succinct manner. Moreover, cognizant of the similarities of 'strongly agree' and 'agree' on the one hand; and 'strongly disagree' and 'disagree' on the other except degree, reduction of the five-point scale into a three-point scale was made. To this end, the values of the options 'strongly agree' and 'agree' were combined. By the same token, the values of the alternatives 'strongly disagree' and 'disagree' were summed up. This resulted in having a Likert-scale with only three columns, i.e. agree, undecided, and disagree. Hence, the upcoming results and discussions were made based on the three-point scale table.

\subsection{Action Research or Practical Research}

This module has 88 pages in total and consists of three units. Unit one deals with the basics of action research, such as its conceptions, aims, characteristics, importance, and types. Unit one also throws light on discussions about tools of data collection and ways of analyzing data. The second unit dwells on the details of how to write a sound action research proposal. The third unit emphasizes the preparation and presentation of an action research project report. In all of the three units, pre-reading activities, unit objectives, contents, and summaries are provided.

The qualitative content analysis showed that multiethnic and multicultural education contents are not totally addressed in any form of Banks' $(2001,2006,2014)$ four approaches of treating ethno-cultural contents in a teacher education curriculum. Here, it could be argued that 'Action Research' as a professional course could be a potential subject through which prospective teachers would practically acquire the fundamental knowledge, skills, and attitudes necessary for managing issues of diversity by engaging in practical and solution-oriented small-scale research activities individually and/or in teams. In support of this argument, Souto-Manning and Mitchell (2010) assert that to make classrooms more inclusive and culturally-responsive, action research, especially collaborative action research, could be a critical tool for gathering invisible and multi-faceted knowledge that researchers as outsiders and teachers as insiders cannot solely record and/or obtain. In addition, Chan (2006 p. 172) argues that "given the role of experience in shaping perceptions of curriculum, we can expect that teachers' practices and beliefs about incorporating culture into the curriculum would be shaped by their own experiences of culture in their school curriculum".

Nonetheless, the results of the qualitative content analysis indicated that components of multicultural education are not incorporated into any part of the teaching material. This finding was confirmed by the result of the quantitative content analysis where the two coders' level of concordance was $100 \%$, indicating the complete absence of issues of multicultural education. Presumably, this might result from the module writer's little awareness about the importance of addressing issues of multicultural education into the teaching materials prepared for the training of prospective teachers and/or it might be due to deliberate negligence.

\subsection{Sociological Perspectives on Teaching and Learning}

This module or study material has 91 pages and consists of four units. Unit one emphasizes the social foundations of teaching and learning process. The second unit deals with major themes such as education and identity, multiculturalism, basic principles of multicultural education, effects and dimensions of multicultural education. The third unit focuses on the essence of education and society such as the relationship between school and society, the role of education in society, and the how of societal participations in school affairs. The fourth unit deals with the techniques helpful for teaching diversified groups. In all of the four units, unit introduction, unit objectives, contents, students' and teacher's activities, and assessment techniques are provided.

The course's main purposes are to help prospective teachers understand the overall school setting and the nature of society in which the school is operating; analyze forms of societal participation in school affairs; and comprehend the role of teachers in fostering school-community relationships. The course may bring the attention of Ethiopian primary school teacher candidates to the social reconstruction ideology where schools are believed to serve as agents of social change for the better.

It could be argued that for prospective teachers who are expected to work in ethno-culturally diverse nations like Ethiopia, having a clear understanding of how issues such as language, culture and ethnicity influence students' learning is extremely important. This is because learning is culture dependent. This, on the contrary, shows that the training of the teacher candidates is assumed to take issues of diversity into consideration. In addition, if a teacher education curriculum is to serve societal interest, one expects it to be designed in a way that addresses the society's culture, language, history, and tradition so that the prospective teachers are acquainted with adequate 
knowledge, skills, and attitudes necessary to preserve as well as sustain those important attributes in a fair way.

Likewise, the qualitative content analysis revealed that issues of multicultural education are somehow incorporated into the course 'Sociological Perspectives on Teaching and Learning'. In other words, whereas the course 'Sociological Perspectives on Teaching and Learning' is suitable for integrating issues of multicultural education into the entire module in a harmonized manner, those components are entertained only in two of the four units included in the module. The results of the quantitative content analysis i.e. the two coders' level of concordance is $91.66 \%$. This means that, out of the 12 indicators applied, the coders came to agree on 11 of the options that showed presence of multicultural contents in the course 'Sociological Perspectives on Teaching and Learning'. In other words, although issues of multicultural education are incorporated only in two of the four chapters included in the course, the coders came to the agreement that issues of diversity are effectively addressed in the module. This may emanate from the fact that the coders were positively influenced by the incorporation of multicultural components in the primary teacher education curriculum under consideration although this practice is not a common phenomenon in the Ethiopian context.

\subsection{General Methods of Teaching}

This module has 49 pages and has four chapters. Chapter one deals with the essence of teaching as a profession in which the definitions of a profession, criteria to be fulfilled by a profession, professional code of ethics of teaching profession, qualities and responsibilities of an effective teacher are presented turn by turn. Chapter two emphasizes approaches of teaching such as the teacher-centered and student-centered methods of teaching. The chapter also deals with the factors influencing the selection of methods of teaching such as the objectives, contents, instructional facilities, and students' preferences and the likes. Chapter three deals with the details of instructional planning such as the definitions, characteristics, and significances of instructional planning. The chapter further discusses about the basic questions to be answered before planning a given instructional activity. Lastly, chapter four presents the details of classroom organization and management.

As can be realized from the way the course 'General Methods of Teaching' is structured, it could be argued that basic elements of multicultural education could be infused into the entire course so that integration within the course itself as well as across the other courses could easily be maintained. Nevertheless, the results of the qualitative content analysis revealed that fundamental elements of multicultural education are missing in the course. This is also supported by the two coders' concordance of $100 \%$, indicating complete absence of multicultural education contents.

According to Garmon (2005), prospective teachers' preparation for teaching in a multicultural setting could involve commitment to the preparation of teachers to serve students of all social and cultural backgrounds without any partiality. In this regard, the new practice of prospective teachers' preparation involves recognition that learning to teach is a process that continues throughout a teacher's professional career and that no matter what we do in our initial teacher education programs and no matter how well we do it, at best, we can only prepare teachers to begin teaching (Egne, 2014a). Accordingly, teacher educators must help prospective teachers to take responsibility for their own professional development. In light of this argument, one could therefore, claim that Ethiopian primary teacher education program is not preparing the prospective teachers for the type of multicultural setting awaiting them. This may emanate from lack of awareness about the importance of integrating issues of multicultural education into the study material by the writer and/or the writer might deliberately downplay these issues due to his/her personal and/or political outlook.

This, on the other hand, implies that if issues of multicultural education are missing in a course which is assumed to be more suitable for those kinds of matters, it is less likely that issues of diversity are incorporated into the rest of the teacher education courses. In addition, the absence of elements of multicultural education in the course 'General Methods of Teaching' may imply that what is being taught under the auspices of the Ethiopian primary teacher education program is not reflective of the diversity that characterizes the Ethiopian society.

\subsection{Special Needs Education}

This module has 153 pages and nine chapters. The first chapter deals with basic conceptual definitions with respect to special needs education, historical development of special needs education in Ethiopia, legal and policy issues concerning special needs education within the Ethiopian context, and related topics. The second and third chapters discuss about issues related to visual and hearing impairments respectively. The fourth chapter focuses on the essence of mental retardation and how to effectively teach mentally retarded children. The fifth chapter deals with the teaching of children with physical impairment. The sixth chapter discusses issues related to teaching children with learning disabilities. The seventh chapter concentrates on issues related to the teaching of students who have language and communication disorders. The eighth chapter deals with treating children with behavioral and emotional disorders. The last chapter highlights the how of teaching the gifted and talented children.

As can be realized from the theoretical and empirical literature dealing with issues of multicultural education, 'special needs education' is one of the core components of multicultural education (Grant \& Sleeter, 2010; Nieto 
\& Bode, 2010). However, the results of the qualitative content analysis revealed that except dealing with students who have various impairments and the talented ones, issues related to the culturally, linguistically, and ethnologically disadvantaged students and how to help them overcome their problems as well as issues related to the application of culturally responsive pedagogy (Gay, 2010) are totally not included in the module. This claim is also supported with the results of the quantitative content analysis in which the level of agreement between the two coders is found to be $83.33 \%$. This means that, out of the 12 indicators used, the coders came to agree on 10 of the alternatives that showed complete absence of multicultural education contents in the primary teacher education curriculum under consideration.

\subsection{Civic and Ethical Education}

This study material has 37 pages and five units. Unit one illustrates topics such as historical development of civic education, relationship of civic education with other social science disciples, and goals and objectives of civic education. Unit two explains the details of ethics such as its meaning, the idea of morality and ethics, the application of morality at personal and social levels. Unit three dwells on citizenship and patriotism in which it discusses origin of citizenship, modes of attaining citizenship, dual and multiple citizenship, patriotism, and the link between patriotism and citizenship. Unit four describes the details of the concept of democracy. Lastly, unit five elucidates the notions revolving around state and government.

As can be noted from the aforementioned paragraph, civic and ethical education is an interdisciplinary subject. This, in turn, means such subject most likely creates the opportunity to integrate issues of multicultural education even across different subjects (Banks, 2004; Egne, 2010; Torres, 1998). However, results of the qualitative content analysis revealed that elements of multicultural education are largely missing in the subject. This argumentation is also supported by the two coders' concordance of $100 \%$. This raises another concern, i.e., if basic elements of multicultural education are missing in such related subject such as 'civic and ethical education'; it is less likely to find those components in the other primary teacher education curricula of the country.

\section{Conclusions and Implications}

Addressing issues of multicultural education in the teacher education programs are high on the agenda worldwide especially in countries characterized by diversity. Nevertheless, although Ethiopia can be characterized as a mosaic consisting of well over 80 ethnic as well as linguistic groups, basic elements of multicultural education are to a large extent missing in the overall primary teacher education curricula of the country. This means, the primary teacher education curricula are not designed in a way in which the prospective teachers learn about the diverse nature of the Ethiopian society.

In other words, even though there are certain initial ideas that are made to gear the Ethiopian primary teacher education curricula towards multiculturalism as stipulated in the Education and Training Policy of the country, these have not been sufficiently demonstrated in the development of the five-sample primary teacher education curricula. Under such circumstances, it is difficult to foster the learning outcomes of students who come to school from diverse backgrounds as learning is mainly culture dependent. In addition, the findings of the study revealed that there is no significant difference among the Ethiopian primary teacher education curricula in terms of addressing issues of multicultural education. Put differently, there is a very minimum level of incorporating issues of multicultural education into the country's primary teacher education curricula.

On the basis of these findings, one could argue that it is necessary to incorporate basic components of crosscultural education (Banks, 2014; Reysen \& Katzarska-Miller, 2013) into the primary teacher education curricula in an integrated manner so that they could reinforce each other in a positive way in equipping the prospective teachers with the cultural competence necessary for teaching in a multicultural setting. Moreover, while attempting to do justice to all the cultures of the nations and nationalities of Ethiopia, for the sake of manageability, it is important to incorporate the cultures of at least the major ethnic groups, namely Oromo, Amhara, Somali, Tigre, Sidama who constitute $34.5 \%, 26.9 \%, 6.2 \%, 6.1 \%$, and $4.0 \%$ of the total population respectively (Federal Democratic Republic of Ethiopia Population Census Commission, 2008, p. 16) into the entire primary teacher education curricula. This attempt is assumed to help the prospective teachers gain cross-cultural experiences helpful for ensuring mutual understanding, tolerance, and sustainability among the Ethiopian diverse learners.

To this end, amongst other things, the knowledge, skills and attitudes of the experts who are in charge of the development of the teacher education curricula must be significantly improved with respect to issues of multicultural education. Thus, the concerned body is expected to provide sustainable trainings that focus on how to permeate issues of multicultural education into the entire primary teacher education curricula in a fair manner to the experts. As part of this effort, it is important to make sure that those trainings help the experts to bring real attitudinal changes concerning issues of diversity through challenging their deep-seated preconceived attitudes (Rosaen, 2003).

Furthermore, it is of relevance for the concerned body to develop a clear guideline which indicates how to develop teacher education curricula through balancing ethnic identity and national unity, indigenous knowledge 
and international knowledge, and the likes. Furthermore, it is necessary that the experts who design the primary teacher education curricula at the central level are representatives of at least the major ethnic groups outlined above. This representation is important, amongst other things, to get specific cultural contents and inputs that should be incorporated into the curricula from the various ethno-cultural groups of the country.

To sum up, this study has several potential implications for multicultural education policy and practice. With regard to multicultural education policy, this investigation can be considered as an important step in examining how issues of multicultural education are addressed in the primary teacher education policies of Ethiopia and other multicultural states. As part of this contribution, this study may pave the way for the development of multicultural teacher education policies which may serve as guidelines for educational administrators and teacher educators concerning how to plan, deliver, and assess issues of multicultural education in teacher preparation curricula (Vavrus, 2002; Zeichner et al., 1998). Besides, concerning its implication to practice, this study is assumed to contribute to the efforts made to actually produce student teachers who are agents of changes for the better as a consequence of having in-depth understanding about issues of multicultural education thereby applying them in the instructional process to enhance the learning outcomes of primary school students.

\section{References}

Avalos, B. (2000). Policies for teacher education in developing countries. International Journal of Educational Research, 33, 457-474.

Banks, J. A. (2014). An introduction to multicultural education (5 $5^{\text {th }}$ ed.), Boston: Pearson.

Banks, J. A. (2010). Multicultural education: Characteristics and goals. In J. A. Banks, and C. M. Banks (eds.), Multicultural education: Issues and perspective ( $7^{\text {th }}$ ed., pp. 1-32). Hoboken: John Wiley and Sons, Inc.

Banks, J. A. (2006). Race, culture, and education: The selected works of James A. Banks. London: Routledge.

Banks, J. A. (2004). Teaching for social justice, diversity, and citizenship in a global world. The Educational Forum, 68(4), 296-305.

Banks, J. A. (2001). Multicultural education: Characteristics and goals. In J. A. Banks and C. A. M. Banks (eds.), Multicultural education: Issues and perspectives ( $4^{\text {th }}$ ed., pp.1-31). Boston: Allyn and Bacon.

Bennett, C. I. (2011). Comprehensive multicultural education: Theory and practice ( $7^{\text {th }}$ ed.). Boston: Pearson.

Bieger, E. M. (1995). Promoting multicultural education through a literature-based approach. The Reading Teacher, 49(4), 308-312.

Chan, E. (2006). Teacher experiences of culture in the curriculum. Journal of Curriculum Studies, 39(2), 161-176.

Chavez, L. (1998). Civic education in a changing society. In A. M. Melzer, J. Weinberger, and M. R. Zinman (eds.), Multiculturalism and the American democracy (pp. 165-172). Lawrence, KS: University Press of Kansas.

Cochran-Smith, M. (2003). The multiple meanings of multicultural teacher education: A conceptual framework. Teacher Education Quarterly, 7-26.

Dejen, W. (2017). Assessing Ethiopian primary school second cycle social studies textbooks for adequate reflections of multiculturalism. Journal of Education and Practice, 8(10), 17-126.

Egne, R. M. (2017). Perceptions and practices of multicultural education among Ethiopian secondary teacher education program officials, teacher educators, and prospective teachers". Teacher Development, 21(3), 422444.

Egne, R. M. (2015). Ethiopia in transition: A multicultural education perspective in secondary teacher education policies, curricula, and practices. $\mathrm{PhD}$ dissertation, University of Oslo, Norway: Akademika Publishing.

Egne, R. M. (2014a). Representation of the Ethiopian multicultural society in secondary teacher education curricula. Journal of Teacher Education for Sustainability, 16 (1), 54-75.

Egne, R. M. (2014b). Gender equality in public higher education institutions of Ethiopia: The case of science, technology, engineering, and mathematics. Discourse and Communication for Sustainable Education, 5(1), $1-26$.

Egne, R. M. (2010). Washback effects of handouts on the teaching and learning process in higher education institutions in Ethiopia: Adama University in focus. Journal of Teacher Education for Sustainability, 12(2), 129-141.

Elmeroth, E. (2009). Student attitudes towards diversity in Sweden. Intercultural Education, 20(4), 333-344.

Ethiopian Ministry of Information. (2004). Facts about Ethiopia. Addis Ababa: Press and Audiovisual Department.

Federal Democratic Republic Government of Ethiopia. (1994). Education and training policy. Addis Ababa: Berhanena Selam Printing Enterprise.

Federal Democratic Republic of Ethiopia. (1997). Cultural policy. Retrieved 4 March 2020 from http://www.ethioembassy.org.uk/fact\%20file/a-z/culture.htm.

Federal Democratic Republic of Ethiopia. (1995). The constitution of the Federal Democratic Republic of Ethiopia. Addis Ababa: Berhanena Selam Printing Enterprise.

Federal Democratic Republic of Ethiopia, Population Census Commission. (2008). Summary and statistical report 
of the 2007 population and housing census: Population size by age and sex. Retrieved 11 March 2020 from http://www.csa.gov.et/pdf/Cen2007_firstdraft.pdf

Garmon, M. A. (2005). Six key factors for changing preservice teachers 'attitudes/beliefs about diversity. Educational Studies: A Journal of the American Educational Studies Association, 38(3), 275-286.

Gay, G. (2013). Teaching to and through cultural diversity. Curriculum Inquiry, 43(1), 49-70.

Gay, G. (2010). Culturally responsive teaching: Theory, research, and practice (2 ${ }^{\text {nd }}$ ed.), New York: Teachers College Press.

Grant, C. A., \& Sleeter, C. E. (2010). Race, class, gender, and disability in the classroom. In J. A. Banks and C. A. M. Banks (Eds.), Multicultural education: Issues and perspectives ( $7^{\text {th }}$ ed., pp. 59-80), United States of America: John Wiley \& Sons, Inc.

Jenks, C., Lee, J. O., \& Kanpol, B. (2001). Approaches to multicultural education in preservice teacher education: Philosophical frameworks and models for teaching. The Urban Review, 33(2), 87-105.

Kibret, B. W. (2019). A brief overview of multicultural education in Ethiopia: A review. Journal of Philosophy, Culture and Religion, 42, 9-15.

Mergo, B. (2008). Retrospects and prospects of multicultural teacher education in the higher education institutions of Ethiopia: Adama University in focus. The Ethiopian Journal of Education, 28(2), 73-100.

Nieto, S., \& Bode, P. (2010). Multicultural education and school reform. In S. Nieto (Ed.), Language, culture, and teaching: Critical perspectives ( $2^{\text {nd }}$ ed.), New York: Routledge.

Pankajam, G. (2005). Pre-primary education: Philosophy and practice. New Delhi: Concept Publishing Company.

Parekh, B. (2006). Rethinking multiculturalism: Cultural diversity and political theory ( $2^{\text {nd }}$ ed.), Houndmills: Palgrave Macmillan.

Reed, D. F. (1993). Multicultural education for preservice students. Action in Teacher Education, 15(3), 27-34.

Reysen, S., \& Katzarska-Miller, I. (2013). A model of global citizenship: Antecedents and outcomes. International Journal of Psychology, 48(5), 858-870.

Rosaen, C. L. (2003). Preparing teachers for diverse classrooms: Creating public and private spaces to explore culture through poetry writing. Teachers College Record, 105(8), 1437-1485.

Sarantakos, S. (2005). Social research ( ${ }^{\text {rd }}$ ed.), New York: Palgrave Macmillan.

Schlesinger, A. M. (1992). The disuniting of America: Reflection on a multicultural society. New York: Norton.

Silverman, D. (2006). Interpreting qualitative data ( ${ }^{\text {rd }}$ ed.). Los Angeles: Sage Publications Ltd.

Sobel, D. M., Gutierrez, C., Zion, S., \& Blanchett, W. (2011). Deepening culturally responsive understandings within a teacher preparation program: It's a process. Teacher Development: An International Journal of Teachers' Professional Development, 15(4), 435-452.

Souto-Manning, M., \& Mitchell, C. H. (2010). The role of action research in fostering culturally-responsive practices in a preschool classroom. Early Childhood Education Journal, 37(6), 269-277.

Sowell, T. (1993). Inside American education: The decline, the deception, the dogmas. New York: The Free Press.

Terefe, D. (2016). Imperatives of multicultural education in Ethiopia: Reflections on awareness, practices, and challenges in our higher learning institutions. Journal of Culture, Society and Development, 22, 39-50.

Torres, C. A. (1998). Democracy, education, and multiculturalism: Dilemmas of citizenship in a global world. Lanham: Rowman \& Littlefield Publishers, Inc.

Vavrus, M. (2002). Transforming the multicultural education of teachers: Theory, research, and practice. New York: Teachers College Press.

Yang, Y., \& Montgomery, D. (2013). Gaps or bridges in multicultural education: A Q study of attitudes toward student diversity. Teaching and Teacher Education: An International Journal of Research and Study, 30, 2737.

Zeichner, K. M., Grant, C., Gay, G., Gillette, M., Valli, L., \& Villegas, A. M. (1998). A research informed vision of good practice in multicultural teacher education: Design principles. Theory into Practice, 37(2), 163-171.

Zirkel, S. (2008). The influence of multicultural educational practices on student outcomes and intergroup relations. Teachers College Record, 110 (6), 1147-1181.

\section{Acknowledgement}

I would like to thank all the people who assisted me in the course of this research process. In this regard, I would like to extend my gratitude particularly to the instructors who helped me code the sample teaching materials. 